\title{
Gestation length and birth weight in relation to intake of marine $n-3$ fatty acids
}

\author{
BY SJÚRĐUR F. OLSEN* \\ Institute of Epidemiology and Social Medicine, University of Arhus, Høegh-Guldbergsgade 8, \\ DK-Århus C, Denmark \\ AND HARALD S. HANSEN \\ Department of Biological Sciences, Royal Danish School of Pharmacy, Copenhagen, Denmark
}

AND NIELS J. SECHER

Department of Obstetrics and Gynecology, University Hospital of Århus, Arhus, Denmark

AND BENNY JENSEN

Technological Laboratory, Ministry of Fisheries, Technical University, Lyngby, Denmark

AND BRITTMARIE SANDSTRÖM

Research Department of Human Nutrition, Royal Veterinary and Agricultural University, Copenhagen, Denmark

(Received 6 September 1993 - Revised 15 June 1994 - Accepted 24 June 1994)

\begin{abstract}
It has been hypothesized that marine $n-3$ fatty acids ingested during pregnancy prolong duration of pregnancy and increase fetal growth rate in humans. By a combined self-administered questionnaire and interview applied in the 30th week of gestation we assessed dietary intake of marine $n-3$ fatty acids and energy in a population-based sample of 965 pregnant Danish women; in a random $14 \%$ subsample we also measured marine $n-3$ fatty acids relative to arachidonic acid (FA-ratio) in erythrocytes. Mean intake of marine $n-3$ fatty acids was $0.25(95 \%$ range $0-0.75) \mathrm{g} / \mathrm{d}$. We could detect no association between $n-3$ fatty acid intake and FA-ratio on the one hand, and gestation length, birth weight and birth length on the other. The analyses were adjusted for maternal height, prepregnant weight, parity and smoking. The conclusion from the study was that within the intake range of this population, marine $n-3$ fatty acids ingested in the weeks prior to the 30 th week of pregnancy seem not to be a predictor of gestation length or fetal growth rate.
\end{abstract}

Birth weight: Dietary methods: Gestation length: Marine $\boldsymbol{n - 3}$ fatty acids

Over the last two decades, dietary $n-3$ fatty acids of marine origin (particularly eicosapentaenoic acid, 20:5n-3, and docosahexaenoic acid, 22:6n-3) have gained increasing medical attention (Simopoulos et al. 1991). In pregnancy they have been hypothesized to be involved in determining the length of pregnancy, pre-eclampsia risk, and fetal growth. Supplementation with marine $n-3$ fatty acids seems to prolong the duration of pregnancy (Olsen et al. 1992), possibly by changing the balance between stimulatory and inhibitory prostaglandins involved in the process of parturition (Olsen et al. 1986). Dietary marine $n-3$ fatty acids may reduce pre-eclampsia risk by increasing the physiologically active prostacyclin : thromboxane ratio (Dyerberg \& Bang, 1985) and by reducing blood viscosity,

* Present address: Danish Epidemiology Science Centre, 5 Artillerivej, DK-2300 Copenhagen S, Denmark. 
both of which would facilitate placental blood flow, and by reducing blood pressure (England et al. 1987; Secher \& Olsen, 1990). A possible facilitated placental blood flow might also improve the opportunities for fetal growth (Andersen et al. 1989; Olsen et al. 1990).

We quantified the intake of marine $n-3$ fatty acids by a combined self-administered questionnaire and an interview applied in the 30th week of gestation, in a Danish population-based cohort of pregnant women. On a random subsample, intake was also assessed qualitatively by a biochemical marker method ( $n-3$ fatty acids measured in erythrocytes). In the present paper we examine the cohort data with respect to evidence relating to the above hypotheses.

\section{POPULATIONS AND METHODS \\ Study design}

The study ran from 15 April 1988 to 15 January 1989, interrupted by a 3-week period in August 1988. Eligible women were those scheduled to attend the routine 30 th week antenatal visit at a midwifery practice that covers a geographically well-defined area of the city of Århus in Denmark. Among eligible women, $80 \%$ (965 out of 1212) were enrolled. Among women enrolled, a random sample of $14 \%$ had their erythrocytes analysed for fatty acids. The protocol was approved by the Regional Scientific-Ethical Committee of the county of Arrhus, Denmark.

\section{Dietary data}

The dietary method employed a mailed self-administered questionnaire followed by a 15 min structured interview in the 30 th week of gestation, and has been described in detail in another paper (Olsen et al. 1995). The method was designed specifically to quantify intake of marine $n-3$ fatty acids and energy in an epidemiological study. The women were asked to let the reported intakes represent the latest 3 months. Nutrient density is employed rather than daily intake of marine $n-3$ fatty acids, as nutrient density tended to correlate better with biochemically measured levels of long-chain $n-3$ fatty acids (Olsen et al. 1995).

\section{Biochemical methods}

Fatty acids were quantified in erythrocytes sampled at the 30 th week of gestation as described elsewhere (Olsen et al. 1995). The ratio of the sum of the three long-chain $n-3$ fatty acids, eicosapentaenoic, docosapentaenoic and docosahexaenoic acid, to arachidonic acid (the FA-ratio) is used as a biochemical marker for the intake during the weeks before the blood sampling (e.g. von Shacky et al. 1985; Popp-Snijders et al. 1986). We used the FA-ratio rather than the sum of the long-chain $n-3$ fatty acids because the ratio tended to correlate more closely with questionnaire-assessed intake of marine $n-3$ fatty acids (Olsen et al. 1995).

\section{Confounders and clinical outcome}

Information on birth weight, birth length and gestational age at delivery was extracted from birth certificates, clinical records and records from antenatal visits. In the mailed questionnaire the women were asked about smoking habits.

Gestational age at delivery was assessed primarily from the date of the last menstrual period. In cases of uncertainty in remembering the date, irregular or prolonged cycles ( $>36 \mathrm{~d}$ ), or if the woman had used the contraceptive pill up to 4 months before the date, information from early ultrasound examination (undertaken in $83 \%$ of the women) was used instead. 
Table 1. Reported intake of marine foods and n-3 fatty acids in the total sample, and levels of erythrocyte fatty acids in a subsample of pregnant women*

\begin{tabular}{|c|c|c|c|c|c|}
\hline & \multirow[b]{2}{*}{ Mean } & \multirow[b]{2}{*}{ SD } & \multicolumn{3}{|c|}{ Percentiles } \\
\hline & & & 20 & 50 & 80 \\
\hline \multicolumn{6}{|l|}{ Total sample $(n 965)$} \\
\hline Frequency of open sandwiches with marine foods (per week) & 2.5 & $2 \cdot 5$ & 0 & 2 & 4 \\
\hline Frequency of cooked marine food meals (per month) & $2 \cdot 4$ & $2 \cdot 2$ & 1 & 2 & 4 \\
\hline Quantified intake of marine foods $(\mathrm{g} / \mathrm{d})$ & 27 & 23 & 9 & 23 & 43 \\
\hline Intake of marine $n-3$ fatty acids $(\mathrm{g} / \mathrm{d})$ & 0.25 & $0 \cdot 3$ & 0.04 & $0 \cdot 2$ & $0 \cdot 40$ \\
\hline Intake of marine $n-3$ fatty acids relative to energy $(\mathrm{mg} / \mathrm{MJ})$ & 27 & 31 & 4 & 18 & 41 \\
\hline \multicolumn{6}{|l|}{ Subsample $(n 135)$} \\
\hline Long-chain $n-3$ fatty acids in erythrocytes (\%) & 8.4 & 1.2 & 7.6 & $8 \cdot 4$ & $9 \cdot 3$ \\
\hline FA-ratio in erythrocytes & 0.73 & $0 \cdot 12$ & 0.63 & 0.72 & 0.83 \\
\hline
\end{tabular}

FA-ratio (eicosapentaenoic acid + docosapentaenoic acid + docosahexaenoic acid): arachidonic acid.

* For details of procedures, see Olsen et al. (1995).

Information on pre-eclampsia (blood pressure $\geqslant 140 / 95 \mathrm{mmHg}$ after 20 weeks gestation with proteinuria $\geqslant 0.3 \mathrm{~g} / 1$ in women previously normotensive) was extracted from the clinical records.

\section{Statistical methods}

Analysis of variance (ANOVA) was employed to compare the nutritional groups (defined as quintiles of the nutritional variables) with respect to mean gestational age, birth weight, and birth length. Analysis of covariance, using the multiple classification analysis option in the ANOVA procedure in SPSS (Andrews et al. 1973; SPSS Inc., 1988), was applied to adjust these comparisons for differences between the groups in maternal height, prepregnant weight, parity, age, and smoking; the adjusted deviations from the mean show the relationships between the outcome and the nutritional variables after variation due to the other factors mentioned has been taken into account. These analyses are free of any assumptions as to the shape of the relationship between the nutritional variable and the pregnancy outcome variable.

\section{RESULTS}

Mean intake of marine foods (Table 1) in the study population was $27 \mathrm{~g} / \mathrm{d}$ (the $95 \%$ range of observed values was 0 to $71 \mathrm{~g} / \mathrm{d}$ ). Of the total, $3 \%$ reported to have taken fish-oil supplements. Mean intake of marine $n-3$ fatty acid was $0.25(95 \%$ range 0 to 0.75$) \mathrm{g} / \mathrm{d}$. Mean level of the FA-ratio in maternal erythrocytes was $0.73(95 \%$ range 0.55 to 0.92 ; Table 1).

None of the maternal characteristics given in Table 2 exhibited any clear association with the estimated marine food intake, the intake of marine $n-3$ fatty acids relative to energy, or, in the subsample, with the FA-ratio.

When dividing the women into quintiles of nutrient density of marine $n-3$ fatty acids (Table 3), no differences could be detected between the groups in mean gestation length, birth weight or birth length; adjusting the comparisons for possible differences in potential confounding factors did not alter the results. Neither was it, in the subsample, possible to detect any differences in the effect measures across quintiles of the FA-ratio (Table 4). Applying linear regression models did not change these results. 
Table 2. Marine food intake, marine n-3 fatty acid intake and FA-ratio in erythrocytes, in relation to maternal characteristics*

(Mean values with their standard errors)

\begin{tabular}{|c|c|c|c|c|c|c|c|c|}
\hline & \multicolumn{5}{|c|}{ Total sample } & & & \\
\hline & \multirow[b]{3}{*}{$n$} & \multirow{2}{*}{\multicolumn{2}{|c|}{$\begin{array}{l}\text { Marine food } \\
\text { intake }(g / d)\end{array}$}} & \multirow{2}{*}{\multicolumn{2}{|c|}{$\begin{array}{c}\text { Nutrient density } \\
\text { of marine } n-3 \\
\text { fatty acids } \\
(\mathrm{mg} / \mathrm{MJ})\end{array}$}} & \multicolumn{3}{|c|}{ Subsample } \\
\hline & & & & & & & \multicolumn{2}{|c|}{ FA-ratio } \\
\hline & & Mean & $\mathrm{SE}$ & Mean & SE & $n$ & Mean & SE \\
\hline \multicolumn{9}{|l|}{ Parity } \\
\hline 0 & 555 & $26 \cdot 9$ & 0.95 & $27 \cdot 8$ & 1.48 & 82 & 0.739 & 0.0139 \\
\hline 1 & 306 & $28 \cdot 1$ & $1 \cdot 31$ & $24 \cdot 1$ & $1 \cdot 39$ & 45 & $0 \cdot 703$ & 0.0165 \\
\hline $2+$ & 103 & $28 \cdot 5$ & $2 \cdot 20$ & $27 \cdot 2$ & $2 \cdot 49$ & 10 & 0.724 & 0.0373 \\
\hline \multicolumn{9}{|l|}{ Age (years) } \\
\hline$<24$ & 147 & $26 \cdot 0$ & 1.89 & $27 \cdot 5$ & $2 \cdot 83$ & 23 & 0.702 & 0.016 \\
\hline $25-29$ & 440 & 26.9 & $1 \cdot 37$ & $25 \cdot 9$ & 1.59 & 63 & 0.740 & 0.016 \\
\hline $30-34$ & 284 & $28 \cdot 3$ & 1.44 & $26 \cdot 4$ & $1 \cdot 58$ & 33 & 0.694 & 0.019 \\
\hline $35+$ & 89 & $27 \cdot 8$ & $2 \cdot 14$ & $27 \cdot 8$ & $2 \cdot 79$ & 17 & 0.760 & 0.031 \\
\hline \multicolumn{9}{|c|}{ Prepregnant weight $(\mathrm{kg})$} \\
\hline$<49$ & 70 & $28 \cdot 2$ & 3.47 & $25 \cdot 1$ & $3 \cdot 18$ & 13 & 0.725 & 0.037 \\
\hline $50-59$ & 429 & $28 \cdot 2$ & $1 \cdot 12$ & $27 \cdot 5$ & $1 \cdot 60$ & 57 & 0.722 & 0.014 \\
\hline $60-69$ & 312 & $26 \cdot 3$ & $1 \cdot 19$ & $24 \cdot 8$ & 1.59 & 46 & 0.728 & 0.109 \\
\hline $70+$ & 122 & $25 \cdot 2$ & 1.87 & $27 \cdot 4$ & 3.00 & 16 & 0.763 & 0.031 \\
\hline \multicolumn{9}{|l|}{ Height (m) } \\
\hline$<1.59$ & 74 & $27 \cdot 1$ & $2 \cdot 71$ & $22 \cdot 8$ & $2 \cdot 74$ & 11 & 0.718 & 0.037 \\
\hline $1 \cdot 60-1.64$ & 193 & $24 \cdot 3$ & $1 \cdot 36$ & $26 \cdot 5$ & $2 \cdot 81$ & 31 & 0.728 & 0.020 \\
\hline $1.65-1.69$ & 314 & $27 \cdot 1$ & $1 \cdot 24$ & $25 \cdot 7$ & $1 \cdot 60$ & 50 & 0.721 & $0 \cdot 018$ \\
\hline $1 \cdot 70+$ & 346 & 28.5 & $1 \cdot 31$ & $27 \cdot 7$ & $1 \cdot 61$ & 39 & 0.743 & 0.018 \\
\hline \multicolumn{9}{|c|}{ Smoking (cigarettes/d) } \\
\hline 0 & 554 & $26 \cdot 3$ & 0.95 & $25 \cdot 6$ & $1 \cdot 34$ & 78 & $0 \cdot 738$ & 0.014 \\
\hline $1-5$ & 67 & $27 \cdot 4$ & $3 \cdot 10$ & $22 \cdot 0$ & $2 \cdot 85$ & 9 & 0.684 & 0.036 \\
\hline $6+$ & 237 & $29 \cdot 3$ & 1.52 & $28 \cdot 7$ & $2 \cdot 16$ & 39 & 0.714 & 0.020 \\
\hline
\end{tabular}

FA-ratio (eicosapentaenoic acid + docosapentaenoic acid + docosahexaenoic acid): arachidonic acid.

* For details of procedures, see pp. 398-399.

The fourteen women who developed pre-eclampsia did not differ significantly from other women with respect to intake of $n-3$ fatty acids or the FA-ratio.

\section{DISCUSSION}

The present study did not reveal any association between gestation length, birth weight and birth length on the one hand, and intake of $n-3$ fatty acids in pregnancy on the other, either when the intake was quantified by a semi-quantitative questionnaire method or when it was assessed qualitatively by a biochemical marker method. In a parallel study we validated the questionnaire and biochemical measures against each other (Olsen et al. 1995).

The lack of association with gestation length contrasts with findings from two other studies of ours, undertaken in the same population of pregnant women. In a sample that was considerably smaller than the subsample of the present study (37 v. 135 women) we assessed fatty acids in erythrocytes obtained within $2 \mathrm{~d}$ of delivery; we found that gestation length increased by $5.7(95 \%$ confidence interval 1.4 to $10 \cdot 1) \mathrm{d}$ for every $20 \%$ increase in 


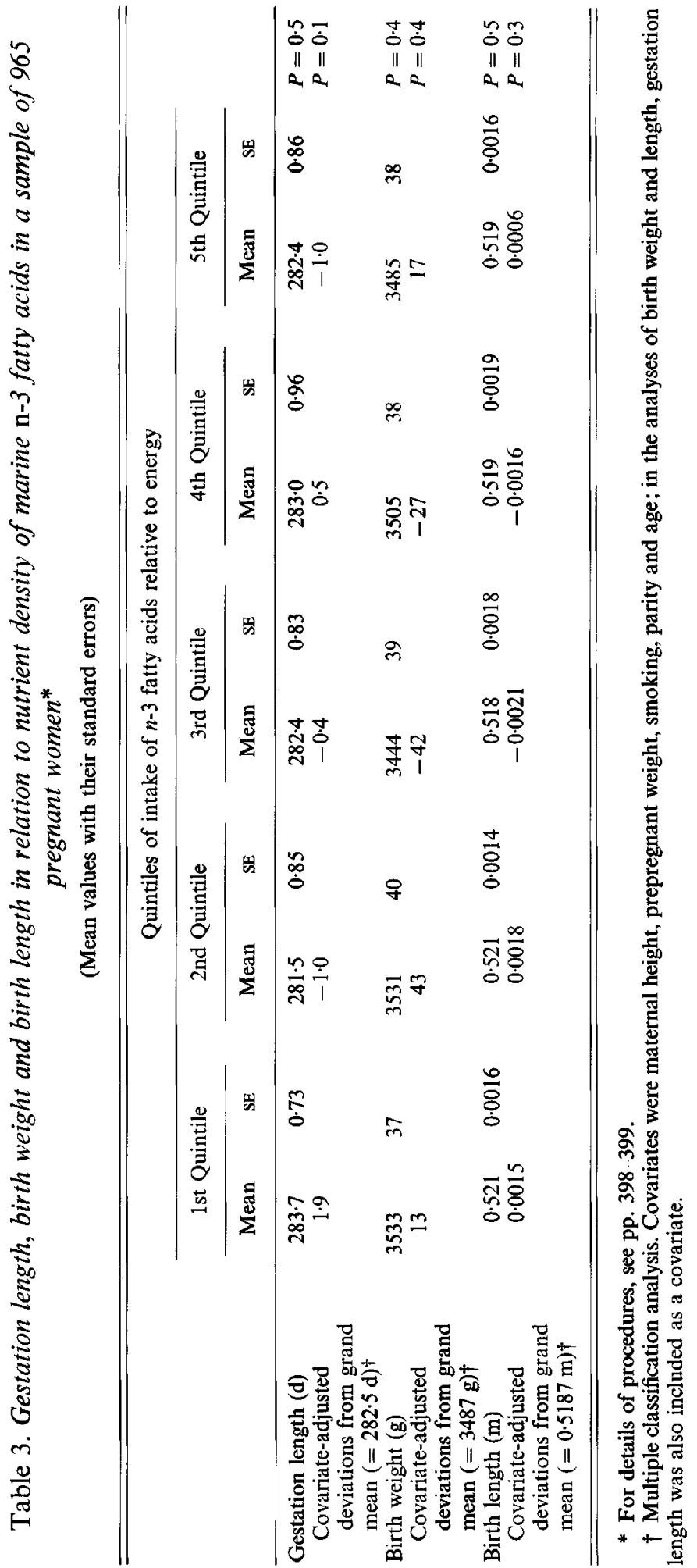




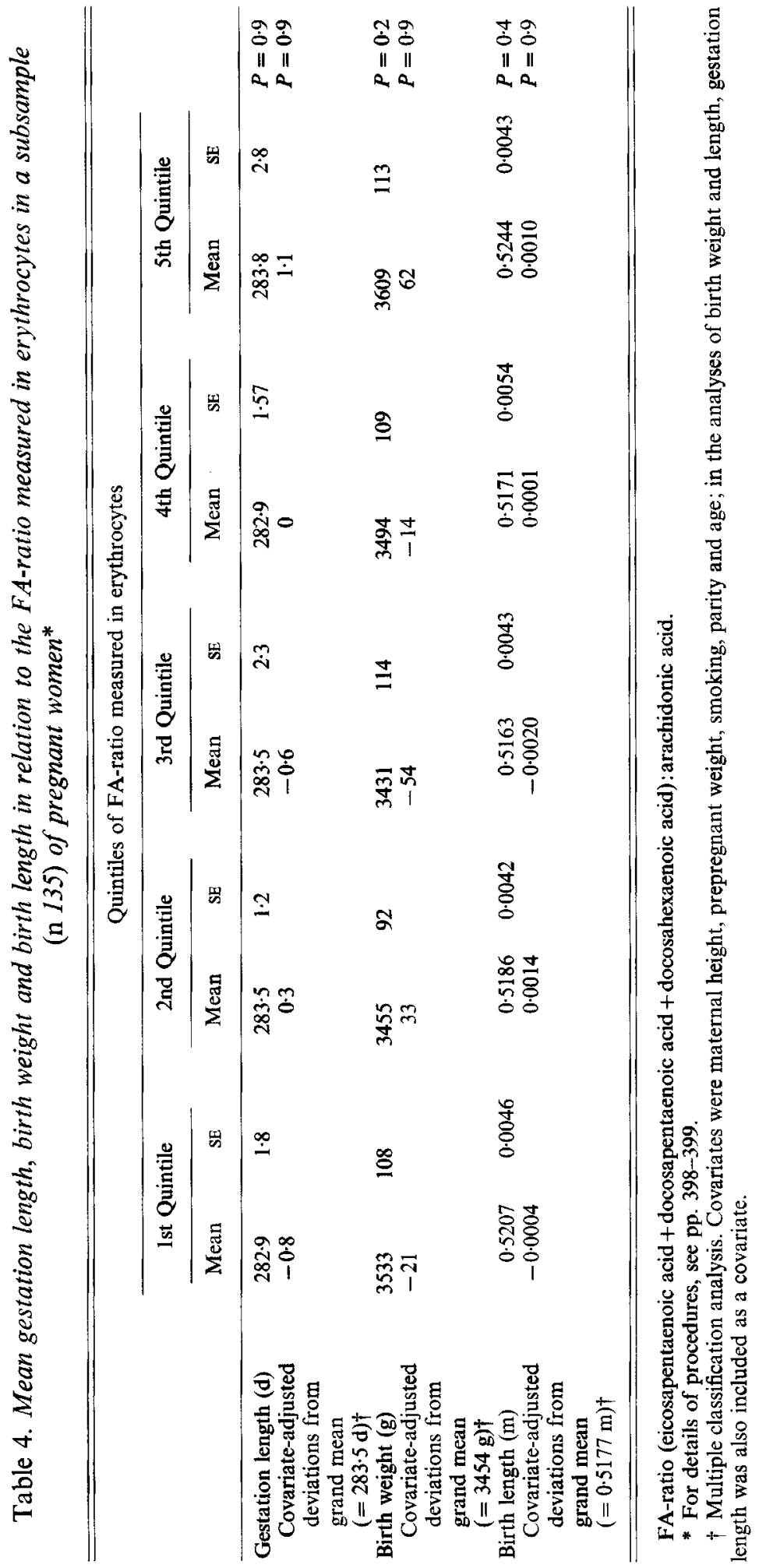


the FA-ratio (Olsen et al. 1991). In a randomized study we supplemented pregnant women from the same population with fish oil, providing $2.7 \mathrm{~g} n-3$ fatty acids/d, or with olive oil from the 30th week of gestation and throughout pregnancy; gestation in the fish-oil group was $4.0(95 \%$ confidence interval 1.5 to 6.4$) \mathrm{d}$ longer than in the olive-oil group (Olsen $e t$ al. 1992). These results indicate that marine $n-3$ fatty acids ingested after the 30th week of gestation prolong gestation length (Olsen et al. 1991, 1992), and that the dose-response relationship is within the intake range of the Danish population (Olsen et al. 1991). In the present study we assessed intake in the months up to the 30th week of gestation, which we would expect to correlate closely with the intake after the 30 th week until delivery. However, the questionnaire and the interview may have increased the women's awareness of their intake of marine $n-3$ fatty acids, because many of the questions were about marine foods and fish oil. We did not inform the participating women about the study hypotheses unless they asked us directly; however, in order to have their cooperation it was necessary to inform the midwives, and they have in general a close contact with the women. In this way, some women may have increased their intake of foods containing $n-3$ fatty acids in the third trimester because they had got the impression that it was good for them or their child. Unfortunately, we have no data to substantiate this possible explanation which remains entirely speculative. However, it underlines the principal problem in studying prospectively the effect of an exposure, liable to changes, that exerts its effect in the period after it has been recorded.

The study was also negative with respect to the hypothesized (Andersen et al. 1989; Olsen et al. 1990) effect of dietary $n-3$ fatty acids on the fetal growth rate. In a study with Danish women (Olsen et al. 1990) a direct association was found between the number of fish meals consumed during 1 month in the third trimester of pregnancy, and birth weight, head circumference and placental weight; the association was only found in non-smokers, however. Restricting the analyses of the present study to non-smokers did not change the results (results not shown) and no data were recorded on head circumference and placental weight. We have no good explanation for the discrepancy between the two studies. The present study had lower statistical power because it was much smaller $965 \mathrm{v} .11765$ women) but, on the other hand, exposure to $n-3$ fatty acids was much better described in the present study. Neither did the study substantiate the hypothesis about a preventive effect of dietary marine $n-3$ fatty acids on pre-eclampsia (Dyerberg \& Bang, 1985; England et al. 1987; Secher \& Olsen, 1990). However, only fourteen women got preeclampsia in the study cohort, and the power to detect any effects was therefore limited.

In conclusion, within the intake range of this population (mean $0.25,95 \%$ range 0 to $0.75 \mathrm{~g} / \mathrm{d}$ ) marine $n-3$ fatty acids ingested in the second trimester of pregnancy seem not to be a predictor of gestation length or fetal growth rate.

The authors had helpful discussions with Professor J. Olsen, Dr K. Overvad and Professor T. I. A. Sørensen. H. B. Hansen and M. Strunge Madsen are acknowledged for their help in designing and processing the food questionnaires, L. Jørgensen for undertaking the interviews and taking the blood samples, and E. Nordstrøm Jensen for the fatty acid analyses. Dr K. Skejaa is thanked for his help, particularly in the data collection and processing. Financial support was given by Weiman's legat, Helsefondet, Statens Lægevidenskabelige Forskningsråd og Egmont H. Petersens Fond.

\section{REFERENCES}

Andersen, H. J., Andersen, L. F. \& Fuchs, A. R. (1989). Diet, pre-eclampsia and intrauterine growth retardation. Lancet i, 1146. 
Andrews, F. K., Morgan, J., Sonquist, J. \& Klein, L. (1973). Multiple Classification Analysis, 2nd ed. Ann Arbor: University of Michigan.

Dodge, J. T. \& Phillips, G. B. (1967). Composition of phospholipids and of phospholipid fatty acids and aldehydes in human red cells. Journal of Lipid Research 8, 667-675.

Dyerberg, J. \& Bang, H. O. (1985). Pre-eclampsia and prostaglandins. Lancet i, 1267.

England, M. J., Atkinson, P. M. \& Sonnendecker, E. W. W. (1987). Pregnancy induced hypertension: will treatment with dietary eicosapentaenoic acid be effective? Medical Hypotheses 24, 179-186.

Olsen, S. F., Hansen, H. S., Sandström, B. \& Jensen, B. (1995). Erythrocyte levels compared with reported dietary intake of marine $n-3$ fatty acids in pregnant women. British Journal of Nutrition 73, 387-395.

Olsen, S. F., Hansen, H. S., Sommer, S., Jensen, B., Sørensen, T. I. A., Secher, N. J. \& Zachariassen, P. (1991). Gestational age in relation to marine $n-3$ fatty acids in maternal erythrocytes: a study of women in the Faroe Islands and Denmark. American Journal of Obstetrics and Gynecology 164, 1203-1209.

Olsen, S. F., Hansen, H. S., Sørensen, T. I. A., Jensen, B., Secher, N. J., Sommer, S. \& Knudsen, L. B. (1986). Intake or marine fat, rich in (n-3)-PUFA, may increase birthweight by prolonging gestation. Lancet ii, $367-369$.

Olsen, S. F., Olsen, J. \& Frische, G. (1990). Does fish consumption during pregnancy increase fetal growth? A study of the size of the newborn, placental weight and gestational age in relation to fish consumption during pregnancy. International Journal of Epidemiology 19, 971-977.

Olsen, S. F., Sørensen, J. D., Secher, N. J., Hedegaard, M., Henriksen, T. B., Hansen, H. S. \& Grant, A. (1992). Randomised controlled trial of effect of fish-oil supplementation on pregnancy duration. Lancet 339, 1003-1007.

Popp-Snijders, C., Schouten, J. A., van Blitterswijk, W. J. \& van der Veen, E. A. (1986). Changes in membrane lipid composition of human erythrocytes after dietary supplementation of $(n-3)$ polyunsaturated fatty acids. Maintenance of membrane fluidity. Biochimica et Biophysica Acta 854, 31-37.

Secher, N. J. \& Olsen, S. F. (1990). Fish oil and pre-eclampsia. British Journal of Obstetrics and Gynaecology 67 , 1077-1079.

Simopoulos, A. P., Kifer, R. R., Martin, R. E. \& Barlow, S. M. (editors) (1991). Health Effects of Omega 3 Polyunsaturated Fatty Acids in Seafoods. World Review of Nutrition and Dietetics 66.

SPSS Inc (1988). SPSS/PC +V2.0 Base Manual for the IBM PC/XT/AT and PS/2. Chicago: SPSS Inc.

von Shacky, C., Fisher, S. \& Weber, P. C. (1985). Long-term effects of dietary marine omega-3 fatty acids upon plasma and cellular lipids, platelet function, and eicosanoid formation in humans. Journal of Clinical Investigation 76, 1626-1631. 